\title{
Intravesical Therapy - BCG and Beyond
}

\author{
H. Barton Grossman ${ }^{\mathrm{a}, *}$, Donald Lamm ${ }^{\mathrm{b}}$, Gottfrid Sjödahl ${ }^{\mathrm{c}, \mathrm{d}}$, Michael O’Donnelle ${ }^{\mathrm{e}}$, Noah Hahn ${ }^{\mathrm{f}, \mathrm{g}}$ \\ and Ashish Kamat ${ }^{\mathrm{a}}$ \\ ${ }^{a}$ Department of Urology, The University of Texas MD Anderson Cancer Center, Houston, TX, USA \\ ${ }^{\mathrm{b}}$ University of Arizona College of Medicine, Phoenix, AZ, USA \\ ${ }^{\mathrm{c}}$ Department of Urology, Skåne University Hospital, Lund, Sweden \\ ${ }^{\mathrm{d}}$ Department of Translational Medicine, Lund University, Malmö, Sweden \\ ${ }^{\mathrm{e}}$ University of Iowa Carver College of Medicine, Department of Urology, Iowa City, IA, USA \\ ${ }^{\mathrm{f}}$ The Sidney Kimmel Comprehensive Cancer Center at Johns Hopkins, Baltimore, MD, USA \\ gJohns Hopkins Greenberg Bladder Cancer Institute, Baltimore, MD, USA
}

Received 5 September 2018

Accepted 21 December 2018

\begin{abstract}
Non-muscle invasive bladder cancer is marked by frequent recurrences and a risk for progression to life threatening disease. Intravesical Bacillus Calmette-Guérin (BCG), one of the earliest effective immunotherapies for cancer, remains the current standard for treating high-risk non-muscle invasive bladder cancer. Optimal treatment with BCG includes periodic 3 weekly maintenance instillations, often with dose reduction to minimize toxicity. However, despite its efficacy, treatment failure is common. Efforts to provide alternate and potentially more effective therapy for this disease include increased understanding of bladder cancer through molecular profiling, multi-agent intravesical chemotherapy, and novel forms of immunotherapy.
\end{abstract}

Keywords: Bladder cancer, BCG, immunotherapy, intravesical chemotherapy, molecular profiling

Over the past few decades, there have been multiple significant and clinically important advances both in knowledge and treatment of urologic diseases in general and more specifically bladder cancer. However, if we narrow the focus to non-muscle invasive bladder cancer, skeptics point out both intravesical Bacillus Calmette-Guérin (BCG) and perioperative intravesical chemotherapy were first reported in 1976 $[1,2]$, and the identification of the variable risks of non-muscle invasive bladder cancer [3], optimization of intravesical BCG [4] and chemotherapy [5], and improvement in the detection of the bladder cancer [6] were all reported more than a decade ago. The critical questions are where are we now and where

\footnotetext{
*Correspondence to: H. Barton Grossman, M.D., 1515 Holcombe Boulevard, Unit 1373, Houston, TX 77030-4009, TX, USA. Tel.: +1 713792 3250; Fax: +1 713794 4824; E-mail: hbgrossman@mdanderson.org.
}

are we going. A good place to start is discussing the strengths and limitations of intravesical BCG.

\section{INTRAVESICAL BCG}

Urologists can boast that the modern age of cancer immunotherapy began with the remarkable success of direct topical immune stimulation using the potent tuberculosis vaccine, BCG that reduced tumor recurrence compared with surgery alone and surgery plus chemotherapy [7-9]. Further experience and the development of 3-week maintenance BCG demonstrated that BCG also reduced disease progression, metastasis and mortality $[4,10,11]$. In carcinoma in situ (CIS), complete response (CR) with BCG is approximately $70 \%$ compared with the $50 \%$ reported with intravesical chemotherapy, and with the addition of 3 weekly maintenance BCG instillations at 
3 months CR increased from $69 \%$ to $84 \%(p=0.01)$ in the SWOG 8507 study. In high-risk, non-muscle invasive bladder cancer (NMIBC) $20 \%$ or less of patients treated with chemotherapy remain recurrence free for 5 years, compared with nearly $50 \%$ of those treated with induction BCG and nearly $80 \%$ of those treated with the 3 week maintenance BCG regimen [4]. Despite this demonstrated efficacy, many patients eventually fail BCG treatment and are at risk of disease progression.

The mechanism of action of BCG is broad, complex and variable. BCG stimulates both humoral and cellular immunity, activates macrophages and is associated with production of multiple beneficial cytokines [12]. Failure to respond to BCG may be due to patient immunological factors, tumor resistance, suboptimal administration, or simply failure to recognize the limitations of BCG immunotherapy. The detection and treatment of immunologic defects and tumor resistance factors are largely unknown so that in the absence of known immunosuppression or other contra-indications such as active tuberculosis, patients who do not have low risk bladder cancer are given $\mathrm{BCG}$ and those who fail receive an alternative treatment. With a response rate of approximately $70 \%$ in CIS [13], and proven reduction in recurrence, progression, and mortality the "try and see" approach makes good sense. How then can we improve BCG treatment? Significant improvement can be made by eliminating common causes of treatment failure.

Despite clear, confirmed level one evidence that 3week maintenance is superior to BCG induction many patients still receive only suboptimal 6-week induction. When such patients fail, they are commonly given a second 6-week induction course despite the absence of level one evidence. On the contrary, a randomized controlled trial of repeated 6 week induction in patients with CR of CIS to induction BCG showed no significant reduction in recurrence of malignancy [14]. Urinary Th1 cytokines peak in BCG nä̈ve patients after the 5th instillation, but with a second or third course beneficial cytokines peak early, suggesting that efficacy, cost and safety can be improved with 3 rather than 6 instillations in previously BCG-treated patients [15]. When a patient fails a second 6-week course one does not know if it is due to tumor resistance or iatrogenic immunosuppression, and those who suffer a serious side effect may be permanently denied the future benefit of maintenance BCG.

Patients who receive optimal BCG may have recurrent disease due to seeding from urothelial carcinoma in the ureters or prostatic ducts, sites that are inaccessible to intravesical instillation and need to be evaluated. Distal ureteral tumors or CIS, seen in as many as $20 \%$ of patients with diffuse CIS or muscle invasive disease undergoing cystectomy, can be treated with resection of the intramural ureter, inducing reflux, or antegrade instillation via ureteral catheter or percutaneous nephrostomy. Urethral carcinoma is seen in approximately $40 \%$ of men undergoing cystoprostatectomy [16] and is a frequently missed site of disease in patients with NMIBC. Urethral disease may respond to intravesical disease, but deep ductal or stromal invasive disease is beyond the reach of intravesical BCG and can grow undetected and progress despite negative cystoscopy and cytology.

Fear of BCG side effects is likely a significant factor in reducing the use of BCG. In a study of 24,000 patients BCG treatment significantly reduced mortality, but fewer than one fourth of patients who were eligible for BCG received it [11]. Simply withholding or logarithmically reducing the dose (by $1 / 3$, not $1 / 2$ ) for patients experiencing increasing side effects will prevent most serious side effects, and prolonged isoniazid and rifampin can effectively treat the remainder. While this can improve treatment with $\mathrm{BCG}$, additional therapies are needed.

\section{MOLECULAR PROFILING OF BLADDER CANCER}

Molecular profiling has transformed our understanding of muscle-invasive bladder cancer (MIBC) biology demonstrating that at least 5 mRNA expression subtypes exist $[17,18]$. Briefly, these are divided into tumors expressing urothelialdifferentiation genes, termed "Luminal-like" and tumors without urothelial-differentiation. The latter correspond to the Basal/Squamous-like subtype and the minor Neuroendocrine-like and Mesenchymallike subtypes. Fewer studies exist for NMIBC, but the data suggest that almost all NMIBC tumors express urothelial-differentiation genes, thus being "Luminal-like" $[19,20]$. We studied the available data on prior NMIBC diagnosis and molecular subtypes in The Cancer Genome Atlas (TCGA) cohort $(n=296)$ of muscle-invasive bladder cancer. Patients with MIBC of the Genomically Unstable subset of Luminal-like tumors and the Small-cell/Neuroendocrine-like subtype were both enriched for prior NMIBC diagnoses (Lund classification, prior NMIBC: $16 / 49 p=0.036$ and 6/13 
$p=0.037$, respectively), whereas patients with the Urothelial-like and Basal/Squamous subtype showed statistically non-significant, lower frequency of prior NMIBC disease (prior NMIBC: 22/126 $p=0.19$, and $11 / 72 p=0.18$, respectively). Preliminary retrospective data from the Lund group indicate that primary as well as recurrent NMIBCs are nearly exclusively Luminal-like, sub-classified as Urothelial-like or Genomically Unstable with the Lund classifier. Multiple non-muscle invasive (NMI) recurrences may arise independently but at the same time share molecular alterations owing to patient specific factors and mutations present in the pre-neoplastic urothelium [21]. Although still under debate, primary tumor, recurrences, and progression tumors are most likely not developing linearly, since most NMI recurrences are new tumor formations occurring at different sites in the bladder compared to prior resected tumors [22]. Instead, a clonal, or oligo-clonal pre-neoplastic urothelial field may develop NMI recurrences and progression with patient specific probabilities over time. This has implications for predicting progression by molecular analysis of NMI tumors, which is possible, and may reach approximately the same effect size as clinico-pathological risk models [23, 24]. Questions that remain include how frequently recurrences change subtypes. Is the patient's risk that of the new subtype, or is the subtype changing process prognostic in itself? These considerations may be relevant for how molecular subtyping can predict progression, and potentially also intravesical treatment failure. It is not known if Urothelial-like, Genomically Unstable, or the rare Basal/Squamous or Neuroendocrine-like NMI tumors, are associated with differential response to BCG, which may be one of the most pressing clinical questions where molecular subtypes could matter. Until the available data and our understanding of molecular subtypes in NMIBC rises to the levels seen in MIBC, the potential clinical utility of molecular subtyping in NMIBC remains unproven.

\section{MULTI-AGENT INTRAVESICAL CHEMOTHERAPY}

Since the FDA approval of Bacillus CalmetteGuerin (BCG), adjuvant intravesical chemotherapy has been relegated primarily to treating those with either intermediate-risk disease or BCG failure. While many early intravesical agents (e. g. thiotepa) have fallen out of favor, several new chemotherapeutic agents (e.g. gemcitabine, docetaxel) have been developed and tested intravesically. While the advantages of multi-agent systemic chemotherapy over single agent treatment have been known for years, little investigation of combination intravesical therapies has been undertaken until recently (Table 1).

In the earliest report of combination intravesical therapy, Fukui et al. reported the results of 30 patients with CIS alone (18 primary disease, 12 recurrent disease) treated with $40 \mathrm{mg}$ doxorubicin,

Table 1

Combination Intravesical Chemotherapy Results

\begin{tabular}{|c|c|c|c|c|c|c|}
\hline Study & Agents & Maintenance & $\begin{array}{l}\text { Patient } \mathrm{n} \\
\text { (BCG-F) }\end{array}$ & $\begin{array}{c}\mathrm{F} / \mathrm{U} \\
\text { (Mo's) }\end{array}$ & $\begin{array}{c}\text { DFS \%@ } \\
\text { 3 Mo's }\end{array}$ & DFS \%@ F/U \\
\hline $\begin{array}{l}\text { Fukui } \\
1989[25]\end{array}$ & $\begin{array}{l}\text { Doxorubicin } \\
\text { Mitomycin }\end{array}$ & $\begin{array}{l}\text { MMC } \\
\text { monthly } \times 1 \mathrm{Yr}\end{array}$ & $30(12)$ & 23 Mo’s & $66 \%$ & 41\%@23 Mo’s \\
\hline $\begin{array}{l}\text { Sekine } \\
1994[26]\end{array}$ & $\begin{array}{l}\text { Doxorubicin } \\
\text { Mitomycin }\end{array}$ & $\begin{array}{l}\text { MMC } \\
\text { monthly } \times 1 \mathrm{Yr}\end{array}$ & $43(17)$ & $45 \mathrm{Mo}$ ’s & $74 \%$ & 44\%@45 Mo’s \\
\hline $\begin{array}{l}\text { Chen } 2012 \\
\text { [27] }\end{array}$ & $\begin{array}{l}\text { Mitomycin } \\
\text { Doxorubicin } \\
\text { Cisplatin }\end{array}$ & $\begin{array}{l}\text { MMC/Dox/Plat } \\
\text { monthly } \times 3 \mathrm{Yr}\end{array}$ & $114(-)$ & 38 Mo's & & 64\%@3Yr \\
\hline $\begin{array}{l}\text { Lightfoot } \\
2014 \text { [28] }\end{array}$ & $\begin{array}{l}\text { Gemcitabine } \\
\text { Mitomycin }\end{array}$ & $\begin{array}{l}\text { Gem-MMC } \\
\text { monthly } \times 1 \text { Yr }\end{array}$ & $47(37)$ & 26 Mo’s & $68 \%$ & $38 \% @ 2 \mathrm{Yr}$ \\
\hline $\begin{array}{l}\text { Cockerill } \\
2016[29]\end{array}$ & $\begin{array}{l}\text { Gemcitabine } \\
\text { Mitomycin }\end{array}$ & none & $27(24)$ & 22 Mo’s & & 37\% @ $22 \mathrm{Mo}$ ’s \\
\hline $\begin{array}{l}\text { Steinberg } \\
2015[30]\end{array}$ & $\begin{array}{l}\text { Gemcitabine } \\
\text { Docetaxel }\end{array}$ & $\begin{array}{l}\text { Gem-Doce } \\
\text { monthly } \times 2 \text { Yr }\end{array}$ & $45(41)$ & 12.5 Mo’s & $66 \%$ & $34 \% @ 2 y r s$ \\
\hline $\begin{array}{l}\text { Milbar } \\
2017[31]\end{array}$ & $\begin{array}{l}\text { Gemcitabine } \\
\text { Docetaxel }\end{array}$ & $\begin{array}{l}(21 \%) \text { Gem-Doce } \\
\text { monthly } \times 2 \text { Yr }\end{array}$ & $33(25)$ & 18.6 Mo’s & & $\begin{array}{l}24 \% @ 2 \mathrm{Yr} \\
\text { overall 42\% } 2 \text { Yr } \\
\text { HG RFS }\end{array}$ \\
\hline $\begin{array}{l}\text { DeCastro } \\
2017 \text { [32] }\end{array}$ & $\begin{array}{l}\text { Cabazitaxel } \\
\text { Gemcitabine } \\
\text { Cisplatin }\end{array}$ & & $8(8)$ & & $88 \%$ & \\
\hline
\end{tabular}

$\mathrm{N}=$ number; $\mathrm{BCG}-\mathrm{F}=\mathrm{BCG}$ failure; $\mathrm{F} / \mathrm{U}=$ Follow up; Mo's=Months; DFS = Disease free survival; $\mathrm{MMC}=$ Mitomycin C $\mathrm{Yr}=$ year ; Dox $=$ doxorubicin $;$ Plat $=$ Cisplatin $;$ Gem $=$ Gemcitabine; Doce $=$ Docetaxel . 
followed by $20 \mathrm{mg}$ mitomycin (MMC) the next day, weekly for 5 weeks [25]. If disease-free after induction, patients received maintenance MMC every 2-4 weeks for 1 year. Nineteen $(63 \%)$ patients had a complete response but 20 patients $(66 \%)$ had moderate to severe bladder irritation (possibly due to the vesicant nature of both drugs). Long-term follow-up revealed 19 of $43(44 \%)$ patients remained disease free at a median follow-up of 45 months, however, $19 \%$ progressed to invasive and/or metastatic disease [26].

Chen et al. reported a retrospective study utilizing a triple-drug regimen of mitomycin, doxorubicin, and cisplatin (MDP) in 114 patients with newly diagnosed papillary NMIBC patients (CIS excluded) [27]. The MDP regimen involved weekly instillation of single-agent chemotherapy in a rotating fashion for six weeks (each drug instilled twice during induction), followed by 3 -week rotating agent maintenance cycles (each drug instilled once during each maintenance cycle) at 3, 6, 12, 18, 24, 30, and 36 weeks. Drug dosing was $30 \mathrm{mg}$ in $30 \mathrm{~mL}$ saline for all agents. The first dose (mitomycin) was typically given as a perioperative instillation. Relapse Free Survival (RFS) at 36 months was similar to 62 patients treated with BCG $(66.1 \%)$ vs. MDP $(63.8 \%)$ despite the MDP cohort having patients with more high-risk features (i.e. multifocality, T1, etc.), yet clearly superior to 65 patients treated with doxorubicin alone (44.6\%). MDP patients had less major adverse events than BCG $(5.8 \%$ vs. $15 \%$, ) but the total discontinuation rates were similar (16.8\% vs. $22.5 \%)$.

Sequential gemcitabine and mitomycin has been used in patients with high-risk bladder cancer. Drugs were administered weekly for 6 weeks, followed by monthly maintenance for 12 months. Patients received $1000 \mathrm{mg}$ gemcitabine $/ 50 \mathrm{~mL}$ saline for 90 minutes, followed by $40 \mathrm{mg}$ mitomycin $/ 20 \mathrm{~mL}$ saline for 90 minutes. The instillation sequence is important as mitomycin will degrade in acidic conditions and reconstituted gemcitabine is acidic $(\mathrm{pH}=2.4)$, and could theoretically inactivate mitomycin if administered concurrently. A multi-institutional pooled analysis of 47 patients (78\% with prior BCG failure) noted a disease free survival of $48 \%$ at 1 year and $38 \%$ at 2 years with good tolerance ( 4 patients required discontinuation of mitomycin due to side effects) [28]. At a median follow up time of 26 months, $21 \%$ of the patients required cystectomy and there were 2 bladder cancer deaths (4\%). Recently, Cockerill et al. validated these findings, noting a RFS of $37 \%$ at 22 months in 27 patients treated with induction therapy alone [29].
Steinberg et al. reported the results of 45 high-risk patients (37 with prior BCG failure, 4 BCG intolerant) treated with $1000 \mathrm{mg}$ gemcitabine/ $50 \mathrm{~mL}$ saline for 1.5 hours, followed by $37.5 \mathrm{mg}$ docetaxel, a nonvesicant, microtubule polymerization stabilizer, in $50 \mathrm{~mL}$ saline for 2 hours, weekly for 6 weeks [30]. Monthly maintenance was performed for 2 years if found to be disease free. Treatment was generally tolerated well with only 5 patients unable to complete full induction. Sixty six percent were disease free at 3 -months, while RFS was $54 \%$ at 1 year and $34 \%$ at 2 years. Ten patients ultimately went on to cystectomy after failure and only a single patient had invasive disease. Milbar, et al. recently confirm these findings in a cohort of 33 patients (66\% with prior BCG failure) [31]. Only $21 \%$ of patients received maintenance therapy. Patients were found to have a $42 \% 1$-year and $24 \%$ 2-year RFS, while the high-grade RFS was 56\% at 1 year and $42 \%$ at 2 years.

DeCastro et al. reported the results of a Phase I trial in a cohort of 9 patients with prior BCG failure and a median of 4 prior intravesical therapies [32]. Treatment included $2000 \mathrm{mg}$ of gemcitabine and an escalating dose of cabazitaxel alone (first 4 patients), then gemcitabine, cabazitaxel $(5 \mathrm{mg})$ and an escalating dose of cisplatin (next 5 patients). Four patients had grade 2 toxicity but all completed induction. Seven of 8 patients had a complete response.

Combination intravesical chemotherapy is an understudied area of NMIBC but has become attractive after the successful introduction of new, better-tolerated and active intravesical drugs such as gemcitabine and docetaxel. While only a handful of studies exist, most show an improvement in initial and durable response with cocktails of two or more agents vs. single agent therapy. This is particularly evident among BCG-unresponsive patients. (Fig. 1) [28-31, 33, 34]. Some treatment protocols (i.e. Gemcitabine/Mitomycin, Gemcitabine/Docetaxel, and Cabazitaxel/Gemcitabine/Cisplatin) show promising early results. Further follow up and comparative analysis to other treatments and in broader NMIBC risk groups are needed to define their ultimate clinical utility.

\section{NEW IMMUNOTHERAPEUTIC APPROACHES}

Improved understanding of the many immunomodulatory mechanisms by which tumors evade anti-neoplastic immune surveillance has 
Gemcitabine with 12 Mo Maintenance: SWOG S0353 31
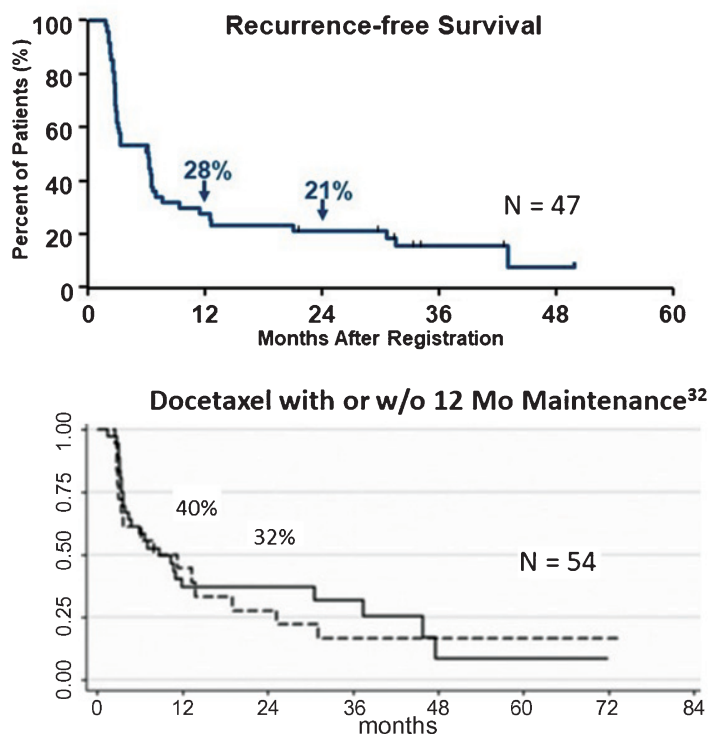

Gemcitabine-Mitomycin with 12 Mo Maintenance ${ }^{26}$
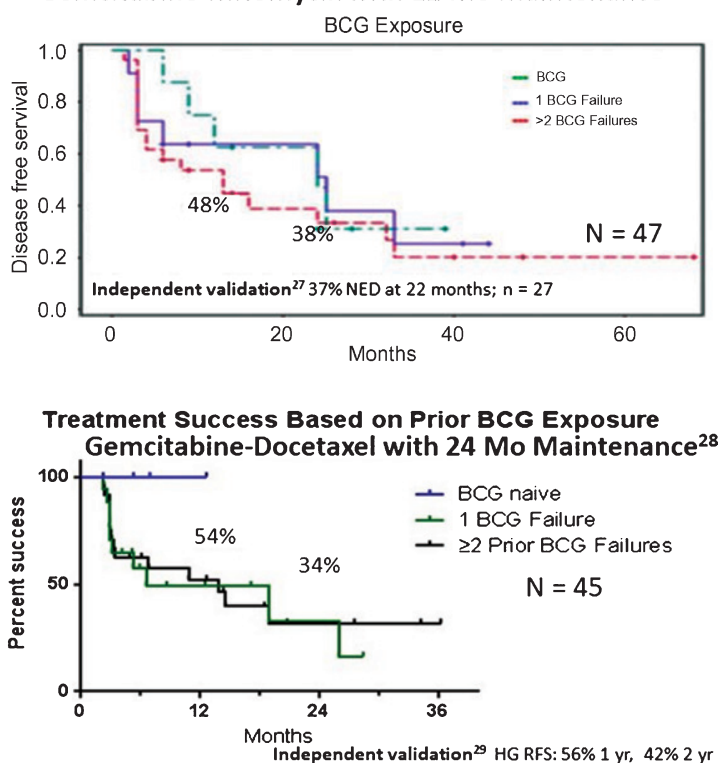

Fig. 1. Early results of rescue therapy after BCG failure with newer agents alone and in combination.

Table 2

Ongoing Intravesical Immunotherapy Studies

\begin{tabular}{|c|c|c|c|c|}
\hline Study & Population & $\mathrm{N}$ & Agents & Endpoints \\
\hline NCT03091660 & High-grade BCG-nä̈e & 969 & $\begin{array}{l}\text { Tokyo vs TICE BCG strain; } \\
\text { BCG-priming dose vs none }\end{array}$ & TTHGR \\
\hline NCT02138734 & High-grade BCG-nä̈e & 256 & ALT-803 & $\begin{array}{l}\text { Safety/MTD/RP2D (phase 1b), } \\
\text { TTR (phase 2b) }\end{array}$ \\
\hline NCT03167151 & Recurrent intermediate risk & 36 & Pembrolizumab + BCG & Safety \\
\hline NCT02015104 & BCG-relapsing & 54 & PANVAC vaccine & DFS \\
\hline NCT02371447 & BCG-relapsing & 45 & VPMBC1002 BCG strain & DLT and RFS \\
\hline NCT02773849 & BCG-unresponsive & 150 & rAD-IFNa/Syn3 & CR rate in CIS patients \\
\hline NCT03022825 & BCG-unresponsive & 100 & ALT-803 & $\mathrm{CR}$ rate in CIS patients \\
\hline NCT02808143 & BCG-unresponsive & 27 & Pembrolizumab & MTD \\
\hline NCT02792192 & $\begin{array}{l}\text { BCG-unresponsive, } \\
\text { relapsing, high-risk naïe }\end{array}$ & 70 & Atezolizumab + BCG & Safety, MTD, $6 \mathrm{~m}$ CR rate \\
\hline NCT03317158 & BCG-unresponsive, relapsing & 186 & Durvalumab + BCG & RFS \\
\hline
\end{tabular}

TTHGR $=$ Time to high-grade recurrence, $\mathrm{MTD}=$ Maximum tolerated dose, $\mathrm{RP} 2 \mathrm{D}=$ Recommended phase 2 dose, $\mathrm{TTR}=\mathrm{Time}$ to recurrence, DFS = Disease-free survival, DLT = Dose limiting toxicity, RFS = Relapse free survival, CR = Complete Response, CIS = Carcinoma in-situ.

enabled the investigation of novel intravesical immunotherapy approaches in NMIBC (Table 2). Ongoing intravesical immunotherapy studies are testing new BCG strains, viral vector gene therapies, intravesical antibody platforms, and combination intravesical BCG and systemic therapy combinations. S1602 will examine both the merits of subcutaneous BCG "priming" vaccination and the BCG strain (Tokyo vs TICE) administered in a randomized phase 3 trial of 969 patients with high grade BCG-naive NMIBC (NCT03091660). Similarly, a phase $1 / 2$ trial of 45 patients with BCG-relapsing NMIBC will test the safety and preliminary efficacy of the VPMBC1002 BCG strain (NCT02371447). For BCG-unresponsive NMIBC, several potential practice-changing trials exist. In a phase 2 trial of 40 patients with BCG-refractory or relapsing NMIBC, an intravesically administered recombinant adenovirus interferon-alpha and Syn 3 vector (rAdIFN $\alpha /$ Syn3) demonstrated a 35\% 12-month RFS [35]. Based on these encouraging initial results, a phase 2 FDA-registration trial of $\mathrm{rAd}-\mathrm{IFN} \alpha / \mathrm{Syn} 3$ in patients with BCG-unresponsive NMIBC is ongoing (NCT02773849). ALT-803, a novel mutated IL-15 ligand (N72D) / IL-15 receptor alpha antibody fusion agent, has safety demonstrated in a phase 1 trial 
of intravesical ALT-803 in combination with BCG in BCG-naïve patients, and a case report example of efficacy in BCG-unresponsive NMIBC patients has been reported [36, 37]. An FDA-registration trial of intravesical ALT-803 combined with BCG in 100 BCG-unresponsive patients is underway (NCT03022825). In parallel, a randomized phase 2 of ALT-803 plus BCG compared to BCG alone is ongoing in 81 patients with BCG-naive NMIBC (NCT02138734). While the merits of systemically administered PD-1/PD-L1 immune checkpoint inhibitor (CPI) therapy are now established in metastatic urothelial carcinoma patients, their role in NMIBC is unknown. Two studies are studying the role of intravesical administration of the PD-1 CPI pembrolizumab either in combination with BCG or alone in 27 and 36 patients respectively (NCT02808143 and NCT03167151). Finally, three studies are examining the novel PANVAC tumor antigen vaccine (NCT02015104) $(n=54)$, the PD-L1 targeting CPI atezolizumab (NCT02792192) $(n=70)$, or the PD-L1 targeting CPI durvalumab (NCT03317158) $(n=186)$ in combination with traditional intravesical BCG therapy. Collectively, these studies illustrate a robust pipeline of novel intravesical immunotherapy approaches that should generate important read outs in the near future.

\section{CONCLUSIONS}

The treatment of non-muscle invasive bladder cancer continues to be challenging. BCG, one of the oldest effective immunotherapies for cancer, remains the current standard of adjuvant treatment. Despite its efficacy, initial failure and subsequent relapse are significant clinical problems. New approaches to address these issues that are currently being investigated involve multi-agent intravesical chemotherapy cocktails and novel immunotherapeutic modalities. It remains to be seen whether advances in our understanding of bladder cancer genomics will facilitate these treatments and guide us towards targeted individualized therapy thereby increasing efficacy and decreasing toxicity for the population of people with non-muscle invasive bladder cancer.

\section{ACKNOWLEDGMENTS}

This manuscript was supported by the Leo \& Anne Albert Institute for Bladder Cancer Care and Research.

\section{CONFLICTS OF INTEREST}

HBG is a paid consultant to Cepheid and receives licensing fees from Abbott Molecular.

DL is a paid consultant to AstraZeneca, Bristol Myers-Squibb, and US Biotest.

GS reports no conflicts.

MO is a paid consultant to Fidia Farmaceuticals, Medical Enterprises, Theralase, Urogen, and Vaxiion and receives research support from Abbott Molecular, Medical Enterprises, Photocure, and Urogen.

$\mathrm{NH}$ is a paid consultant to AstraZeneca, Bristol Myers-Squibb, Ferring, Genentech, Merck, Seattle Genetics, OncoGenex, Rexahn, Pieris, Inovio, Advanced Health, Incyte, Bladder Cancer Academy, TARIS, Principia Biopharm, and Eli Lilly and receives research support from AstraZeneca, Bristol Myers-Squibb, Genentech, Seattle Genetics, OncoGenex, Pieris, Inovio, and Principia Biopharm.

AK is a paid consultant to Abbott Molecular, Arquer, Asieris, AstraZeneca, BioClin, BMS, Cepheid, Eisai, Ferring, Imagin, MDxHealth, Medac, Merck, Pfizer, Photocure, Theralase, and US Biotest and receives research support from FKD and Merck.

\section{REFERENCES}

[1] Morales A, Eidinger D, Bruce AW. Intracavitary Bacillus Calmette-Guerin in the treatment of superficial bladder tumors. J Urol. 1976;116(2):180-3.

[2] Burnand KG, Boyd PJ, Mayo ME, Shuttleworth KE, LloydDavies RW. Single dose intravesical thiotepa as an adjuvant to cystodiathermy in the treatment of transitional cell bladder carcinoma. Br J Urol. 1976;48(1):55-9.

[3] Sylvester RJ, van der Meijden AP, Oosterlinck W, Witjes JA, Bouffioux C, Denis L, Newling DW, Kurth K. Predicting recurrence and progression in individual patients with stage Ta T1 bladder cancer using EORTC risk tables: A combined analysis of 2596 patients from seven EORTC trials. Eur Urol. 2006;49(3):466-5.

[4] Lamm D, Blumenstein B, Crissman J, Montie J, Gottesman J, Lowe B, Sarosdy M, Bohl R, Grossman H, Beck T, Leimert J, Crawford E. Maintenance BCG Immunotherapy in Recurrent Ta, T1 and Carcinoma in situ Transitional Cell Carcinoma: A Randomized Southwest Oncology Group Study. J Urol. 2000;163:1124-9.

[5] Friedrich MG, Pichlmeier U, Schwaibold H, Conrad S, Huland H. Long-term intravesical adjuvant chemotherapy further reduces recurrence rate compared with short-term intravesical chemotherapy and short-term therapy with Bacillus Calmette-Guerin (BCG) in patients with non-muscle-invasive bladder carcinoma. Eur Urol. 2007;52(4):1123-29.

[6] Grossman HB, Gomella L, Fradet Y, Morales A, Presti J, Ritenour C, Nseyo U, Droller MJ. A phase III, multicenter comparison of hexaminolevulinate fluorescence cystoscopy and white light cystoscopy for the detection of superficial 
papillary lesions in patients with bladder cancer. J Urol. 2007;178(1):62-7.

[7] Lamm DL, Thor DE, Harris SC, Reyna JA, Stogdill VD, Radwin HM. Bacillus Calmette-Guerin immunotherapy of superficial bladder cancer. J Urol. 1980;124(1):38-40.

[8] Lamm DL, Blumenstein BA, Crawford ED, Montie JE, Scardino P, Grossman HB, Stanisic TH, Smith JA Jr, Sullivan J, Sarosdy MF, et al. A randomized trial of intravesical doxorubicin and immunotherapy with bacille CalmetteGuerin for transitional-cell carcinoma of the bladder. NEngl J Med. 1991;325(17):1205-9.

[9] Lamm DL, Blumenstein BA, David Crawford E, Crissman JD, Lowe BA, Smith JA, Jr., Sarosdy MF, Schellhammer PF, Sagalowsky AI, Messing EM, Loehrer P, Barton Grossman H. Randomized intergroup comparison of bacillus calmetteguerin immunotherapy and mitomycin $\mathrm{C}$ chemotherapy prophylaxis in superficial transitional cell carcinoma of the bladder a southwest oncology group study. Urol Oncol. 1995;1(3):119-26.

[10] Sylvester RJ, Brausi MA, Kirkels WJ, Hoeltl W, Calais Da Silva F, Powell PH, Prescott S, Kirkali Z, van de Beek C, Gorlia T, de Reijke TM. Long-term efficacy results of EORTC genito-urinary group randomized phase 3 study 30911 comparing intravesical instillations of epirubicin, bacillus Calmette-Guerin, and bacillus Calmette-Guerin plus isoniazid in patients with intermediate- and high-risk stage Ta T1 urothelial carcinoma of the bladder. Eur Urol. 2010;57(5):766-73.

[11] Spencer BA, McBride RB, Hershman DL, Buono D, Herr HW, Benson MC, Gupta-Mohile S, Neugut AI. Adjuvant intravesical bacillus calmette-guerin therapy and survival among elderly patients with non-muscle-invasive bladder cancer. J Oncol Pract. 2013;9(2):92-8.

[12] Gandhi NM, Morales A, Lamm DL. Bacillus CalmetteGuerin immunotherapy for genitourinary cancer. BJU Int. 2013;112(3):288-97.

[13] Sylvester RJ, van der Meijden AP, Witjes JA, Kurth K. Bacillus calmette-guerin versus chemotherapy for the intravesical treatment of patients with carcinoma in situ of the bladder: A meta-analysis of the published results of randomized clinical trials. J Urol. 2005;174(1):86-91.

[14] Palou J, Laguna P, Millan-Rodriguez F, Hall RR, SalvadorBayarri J, Vicente-Rodriguez J. Control group and maintenance treatment with bacillus Calmette-Guerin for carcinoma in situ and/or high grade bladder tumors. J Urol. 2001;165(5):1488-91.

[15] de Reijke TM, De Boer EC, Kurth KH, Schamhart DH. Urinary interleukin-2 monitoring during prolonged bacillus Calmette-Guerin treatment: Can it predict the optimal number of instillations? J Urol. 1999;161(1):67-71.

[16] Patel SG, Cookson MS, Barocas DA, Clark PE, Smith JA, Jr., Chang SS. Risk factors for urothelial carcinoma of the prostate in patients undergoing radical cystoprostatectomy for bladder cancer. BJU Int. 2009;104(7):934-7.

[17] Sjodahl G, Eriksson P, Liedberg F, Hoglund M. Molecular classification of urothelial carcinoma: Global mRNA classification versus tumour-cell phenotype classification. J Pathol. 2017;242(1):113-25.

[18] Robertson AG, Kim J, Al-Ahmadie H, Bellmunt J, Guo G, Cherniack AD, Hinoue T, Laird PW, Hoadley KA, Akbani R, Castro MAA, Gibb EA, Kanchi RS, Gordenin DA, Shukla SA, Sanchez-Vega F, Hansel DE, Czerniak BA, Reuter VE, Su X, de Sa Carvalho B, Chagas VS, Mungall KL, Sadeghi S, Pedamallu CS, Lu Y, Klimczak LJ, Zhang J, Choo C, Ojesina AI, Bullman S, Leraas KM,
Lichtenberg TM, Wu CJ, Schultz N, Getz G, Meyerson M, Mills GB, McConkey DJ, Weinstein JN, Kwiatkowski DJ, Lerner SP. Comprehensive Molecular Characterization of Muscle-Invasive Bladder Cancer. Cell. 2017;171(3):54056.e25.

[19] Sjodahl G, Lauss M, Lovgren K, Chebil G, Gudjonsson S, Veerla S, Patschan O, Aine M, Ferno M, Ringner M, Mansson W, Liedberg F, Lindgren D, Hoglund M. A molecular taxonomy for urothelial carcinoma. Clin Cancer Res. 2012;18(12):3377-86.

[20] Hedegaard J, Lamy P, Nordentoft I, Algaba F, Hoyer S, Ulhoi BP, Vang S, Reinert T, Hermann GG, Mogensen K, Thomsen MBH, Nielsen MM, Marquez M, Segersten U, Aine M, Hoglund M, Birkenkamp-Demtroder K, Fristrup N, Borre M, Hartmann A, Stohr R, Wach S, Keck B, Seitz AK, Nawroth R, Maurer T, Tulic C, Simic T, Junker K, Horstmann M, Harving N, Petersen AC, Calle ML, Steyerberg EW, Beukers W, van Kessel KEM, Jensen JB, Pedersen JS, Malmstrom PU, Malats N, Real FX, Zwarthoff EC, Orntoft TF, Dyrskjot L. Comprehensive Transcriptional Analysis of Early-Stage Urothelial Carcinoma. Cancer Cell. 2016;30(1):27-42.

[21] Hafner C, Knuechel R, Stoehr R, Hartmann A. Clonality of multifocal urothelial carcinomas: 10 years of molecular genetic studies. Int J Cancer. 2002;101(1):1-6.

[22] Melicow MM. Tumors of the urinary bladder: A clinicopathological analysis of over 2500 specimens and biopsies. J Urol. 1955;74(4):498-521.

[23] Patschan O, Sjodahl G, Chebil G, Lovgren K, Lauss M, Gudjonsson S, Kollberg P, Eriksson P, Aine M, Mansson W, Ferno M, Liedberg F, Hoglund M. A Molecular Pathologic Framework for Risk Stratification of Stage T1 Urothelial Carcinoma. Eur Urol. 2015;68(5):824-32; discussion 35-6.

[24] Dyrskjot L, Reinert T, Algaba F, Christensen E, Nieboer D, Hermann GG, Mogensen K, Beukers W, Marquez M, Segersten U, Hoyer S, Ulhoi BP, Hartmann A, Stohr R, Wach S, Nawroth R, Schwamborn K, Tulic C, Simic T, Junker K, Harving N, Petersen AC, Jensen JB, Keck B, Grimm MO, Horstmann M, Maurer T, Steyerberg EW, Zwarthoff EC, Real FX, Malats N, Malmstrom PU, Orntoft TF. Prognostic Impact of a 12-gene Progression Score in Non-muscle-invasive Bladder Cancer: A Prospective Multicentre Validation Study. Eur Urol. 2017;72(3):461-9.

[25] Fukui I, Sekine H, Kihara K, Yamada T, Takeuchi S, Yokokawa M, Kawai T, Hosoda K, Ohwada F, Suzuki S, et al. Intravesical combination chemotherapy with mitomycin $\mathrm{C}$ and doxorubicin for carcinoma in situ of the bladder. $\mathrm{J}$ Urol. 1989;141(3):531-4.

[26] Sekine H, Fukui I, Yamada T, Ohwada F, Yokokawa M, Ohshima H. Intravesical mitomycin $\mathrm{C}$ and doxorubicin sequential therapy for carcinoma in situ of the bladder: A longer followup result. J Urol. 1994;151(1):27-30.

[27] Chen CH, Yang HJ, Shun CT, Huang CY, Huang KH, Yu $\mathrm{HJ}, \mathrm{Pu}$ YS. A cocktail regimen of intravesical mitomycin-C, doxorubicin, and cisplatin (MDP) for non-muscle-invasive bladder cancer. Urol Oncol. 2012;30(4):421-7.

[28] Lightfoot AJ, Breyer BN, Rosevear HM, Erickson BA, Konety BR, O'Donnell MA. Multi-institutional analysis of sequential intravesical gemcitabine and mitomycin $\mathrm{C}$ chemotherapy for non-muscle invasive bladder cancer. Urol Oncol. 2014;32(1):35.e15-9.

[29] Cockerill PA, Knoedler JJ, Frank I, Tarrell R, Karnes RJ. Intravesical gemcitabine in combination with mitomycin $\mathrm{C}$ as salvage treatment in recurrent non-muscle-invasive bladder cancer. BJU Int. 2016;117(3):456-62. 
[30] Steinberg RL, Thomas LJ, O’Donnell MA, Nepple KG. Sequential Intravesical Gemcitabine and Docetaxel for the Salvage Treatment of Non-Muscle Invasive Bladder Cancer. Bladder Cancer. 2015;1:65-72.

[31] Milbar N, Kates M, Chappidi MR, Pederzoli F, Yoshida T, Sankin A, Pierorazio PM, Schoenberg MP, Bivalacqua TJ. Oncological Outcomes of Sequential Intravesical Gemcitabine and Docetaxel in Patients with Non-Muscle Invasive Bladder Cancer. Bladder Cancer. 2017;3:293-303.

[32] DeCastro G, Sui W, Pak J, Abate-Shen C, Lee S, Anderson C, Holder D, McKiernan J. MP15-13 A Phase I trial for the use of intravesical Cabazitaxel, Gemcitabine, and Cisplatin (CGC) in the treatment of BCG-refractory nonmuscle invasive urothelial carcinoma of the bladder. The Journal of Urology. 2017;197(4):e175-e6.

[33] Skinner EC, Goldman B, Sakr WA, Petrylak DP, Lenz HJ, Lee CT, Wilson SS, Benson M, Lerner SP, Tangen CM, Thompson IM. SWOG S0353: Phase II trial of intravesical gemcitabine in patients with nonmuscle invasive bladder cancer and recurrence after 2 prior courses of intravesical bacillus Calmette-Guerin. J Urol. 2013;190(4):1200-4.

[34] Barlow LJ, McKiernan JM, Benson MC. Long-term survival outcomes with intravesical docetaxel for recurrent nonmuscle invasive bladder cancer after previous bacillus Calmette-Guerin therapy. J Urol. 2013;189(3):834-9.

[35] Shore ND, Boorjian SA, Canter DJ, Ogan K, Karsh LI, Downs TM, Gomella LG, Kamat AM, Lotan Y, Svatek RS, Bivalacqua TJ, Grubb RL, 3rd, Krupski TL, Lerner SP, Woods ME, Inman BA, Milowsky MI, Boyd A, Treasure FP, Gregory G, Sawutz DG, Yla-Herttuala S, Parker NR, Dinney CPN. Intravesical rAd-IFNalpha/Syn3 for Patients With High-Grade, Bacillus Calmette-Guerin-Refractory or Relapsed Non-Muscle-Invasive Bladder Cancer: A Phase II Randomized Study. Journal of clinical oncology : Official journal of the American Society of Clinical Oncology. 2017;35(30):3410-6.

[36] Huang J, Schisler J, Wong HC, Rosser CJ, Sterbis J. Intravesical ALT-803 for BCG-unresponsive Bladder Cancer - A Case Report. Urology Case Reports. 2017;14:15-7.

[37] Rosser CJ, Nix J, Ferguson L, Wong HC. MP15-12 PHASE IB TRIAL OF ALT-803, AN IL-15 SUPERAGONIST, PLUS BACILLUS CALMETTE GUERIN (BCG) FOR THE TREATMENT OF BCG-NA\&\#xcf;VE PATIENTS WITH NON-MUSCLE-INVASIVE BLADDER CANCER (NMIBC). The Journal of Urology. 2017;197(4):e175. 